\title{
REFORMA DA EDUCAÇÃO COM A LEI No. 13.415/2017 E GESTÃO DO CONHECIMENTO: FORMANDO CAPITAL INTELECTUAL NA SOCIEDADE DO CONHECIMENTO
}

\author{
Aldenisia Bento de Freitas Giovanni iD1, Reginaldo Aliçandro Bordin (D2 \\ Arthur Gualberto Bacelar da Cruz Urpia iD3
}

\section{Resumo}

No final do século $X X$ e início do século $X X I$, o mundo do trabalho passou por mudanças radicais. A reestruturação produtiva dos meios de produção marcado pela intensificação das tecnologias de informação e comunicação e globalização da economia ditou nova ordem na forma de produzir e viver na sociedade do conhecimento. O estudo aborda a Gestão do Conhecimento (GC) e sua relação com a educação e o conhecimento necessário à formação do sujeito do Ensino Médio após Lei no. 13.415/2017 que altera a Lei de Diretrizes e Bases da Educação Nacional (LDB no. 9.394/1996) e ratifica a Base Nacional Comum Curricular do Ensino Médio (BNCCEM). Objetivou analisar a concepção de conhecimento defendida pela Gestão do Conhecimento presente no currículo do Ensino Médio, após Lei n. 13.415/2017. Utilizou-se da pesquisa bibliográfica analítica exploratória, com abordagem qualitativa, tomando como base documentos norteadores da atual Reforma da Educação, que pressupõem uma formação tecnicista, utilitarista e flexível, para o protagonismo juvenil, construção do projeto de vida e preparação para o mundo do trabalho. $O$ estudo justifica-se porque a temática tem gerado debates e reflexões em torno de um currículo em processo de construção, contexto de disputas econômica, política e ideológica, sua efetivação deverá acontecer até 2022 pelos sistemas escolares. O tema não se esgota nesse estudo e sugere outras análises que possam vislumbrar a valorização de uma educação que atenda as demandas de uma sociedade de incertezas e contradições.

Palavras-chave: Gestão do Conhecimento; Ensino Médio; Reforma da Educação; Lei no. 13.415/2017; BNCCEM

\section{REFORM OF EDUCATION WITH LAW No. 13.415/2017 AND KNOWLEDGE MANAGEMENT: FORMING INTELLECTUAL CAPITAL IN THE KNOWLEDGE SOCIETY}

\section{Abstract}

At the end of the 20th century and the beginning of the 21st century, the world of work underwent radical changes. The productive restructuring of the means of

\footnotetext{
${ }^{1}$ Mestre em Gestão do Conhecimento nas Organizações pelo Programa de Pós-Graduação em Gestão do Conhecimento nas organizações (UNICESUMAR, 2020). Professora do Quadro Próprio do Magistério QPM (SEED-PR, 2020). E-mail: aldenisiagiovanni@seed.pr.gov.br

${ }^{2}$ Doutor e Mestre em Educação pela Universidade Estadual de Maringá, UEM, Pr. É professor da Pontifícia Universidade Católica do Paraná e professor adjunto do Centro de Ensino Superior de Maringá (Unicesumar), no mestrado em Gestão do Conhecimento nas Organizações. Pesquisador do Instituto Cesumar de Ciência, Tecnologia e Inovação (ICETI).

${ }^{3}$ Doutor em Economia pela Universidade Federal do Rio de Janeiro (PPGE - IE/UFRJ). Professor do curso de Mestrado em Gestão do Conhecimento nas Organizações da Universidade Cesumar (UniCesumar).
}

(c) (1) (3) Perspectivas em Diálogo, Naviraí, v. 8, n. 16, p. 105-115, jan./abr. 2021. 
production marked by the intensification of information and communication technologies and the globalization of the economy dictated an order in the way of producing and living in the knowledge society. The study addresses Knowledge Management (KM) and its relationship with education and the knowledge necessary for the formation of high school subjects after Law no. 13,415/2017 that alters the Law of Directives and Bases of National Education (LDB no. 9.394/996) and ratifies the Common National Curriculum for Secondary Education (BNCC-EM). The objective was to analyze the knowledge conception defended by Knowledge Management present in the High School curriculum, after Law no. 13,415/2017. Exploratory analytical bibliographic research was used, based on the guiding documents of the current Education Reform, which presuppose a technician, utilitarian and flexible formation, for the youth protagonism, construction of the life project and preparation for the world of work. The study is justified because the theme has generated debates and reflections around a curriculum in the process of being built, in the context of economic, political and ideological disputes, its effectiveness should happen until 2022 by the school systems. The theme does not end with this study and suggests other analyzes that may envision the valorization of an education that meets the demands of a society of uncertainties and contradictions.

Keywords: Knowledge Management; High school; Education Reform; Law no. 13.415/ 2017; BNCC-EM.

\section{Introdução}

$\mathrm{Na}$ contemporaneidade, o conhecimento tornou-se relevante para as organizações que aprendem. Assim, para se manterem competitivas no cenário econômico de disputas acirradas e de incertezas, se utilizam das ferramentas de Gestão do Conhecimento como recurso operacional de aprendizagem e de seus ativos intelectuais para o alcance da vantagem competitiva sustentável.

Nesse contexto, a escola que não está alheia às transformações e inovações, também é convocada a formar o sujeito que irá compor o capital intelectual dessas organizações. Para tanto, urge por um currículo flexível, pragmático, com ênfase no saber fazer, para o desenvolvimento de competências e habilidades socioemocionais, contibribuindo para com o protagonismo juvenil, a construção do projeto de vida e preparação para o mundo do trabalho, conforme o prescrito na Lei no. 13.415/2017 para a etapa do Ensino Médio.

No final do século XX e início do século XXI, o mundo do trabalho passou por mudanças significativas. A reestruturação produtiva dos meios de produção marcada pelo fordismo/taylorismo e mais tarde pelo toyotismo, marcadamente pela produção flexível, intensificação das tecnologias de informação e comunicação e, globalização da economia, ditou uma nova ordem na forma de produzir e viver a vida, na sociedade do conhecimento.

Considerada uma nova roupagem do modo de produção capitalista que para manter-se eficiente, se estrutura de forma flexível, globalizada e sob a lógica do capital financeiro, cenário em que o conhecimento tornou-se o maior dos ativos organizacionais, devendo sua gestão ser estrategicamente gerenciado para a manutenção da vantagem competitiva. Desse modo, Nonaka e Takeuchi (1997), Davenport e Prusak (1998), Dalkir (2005) e Choo (2003) explicam que a Gestão do 
Conhecimento é um campo em ampla expansão em virtude da complexidade do mundo globalizado do século XXI. Conforme Nonaka e Takeuchi (1997, p. 63) o conhecimento é definido como "crença verdadeira justificada" se apropriando do empirismo presente na filosofia como resultante das experiências dos sujeitos, fazendo correlação com as práticas cotidianas das organizações na contínua tarefa de identificar, socializar e utilizar os novos conhecimentos, incorporando-os em novos produtos e serviços, tecnologias e sistemas, perpetuando a mudança no âmbito das organizações.

A aprendizagem organizacional pressupõe que seus membros analisem suas suposições e crenças, avaliem objetivamente seu conteúdo e sua validade à luz das condições vigentes e de novas evidências, embasados nos conhecimentos tácitos adquiridos nas ações cotidianas favorecendo escolhas assertivas (CHOO, 2003).

De acordo com Davenport e Prusak (1998, p. 6), "conhecimento é mistura fluída de experiência condensada, valores, informação contextual e insight experimentado, o qual proporciona uma estrutura para avaliação e incorporação de novas experiências e informações". Denotando assim a importância das experiências para a compreensão do novo conhecimento. Fato sistematicamente defendido pelo pragmatista John Dewey (1859-1952) que propôs o treinamento manual nas escolas, enaltecendo e incorporando as dimensões sensoriais do fazer, o experimentar e do perceber à educação, vez que o homem é o único ser capaz de reter as experiências por meio da memória, conforme escrito por Galiani (2014), dada a ênfase na experiência para a formação do sujeito no ato de conhecer.

Dalkir (2005) reitera a necessidade das experiências anteriores para a aprendizagem organizacional, e a coordenação deliberada e sistemática de pessoas, processos e sistemas na busca de criação do conhecimento que gera valor, processo que é alimentado por valiosas lições aprendidas e melhores práticas dentro da memória organizacional. A autora refere que desconsiderar as experiências anteriores resulta em prejuízos desperdício à organização, pelo gasto em retrabalho, e tomadas de decisões incertas, com base em informação incompletas.

Esses teóricos da Gestão do Conhecimento destacam que as práticas de Gestão do Conhecimento possibilitam sistematizar o conhecimento produzido e sua inovação mediante ferramentas como a tecnologia, visando à operacionalização dos processos de aprendizagens nas dimensões que envolvem pessoas processos e sitemas. esse sentido, compreendendo que a escola não é neutra, esta também é convocada a formar o indivíduo que irá compor o ativo intangível das organizações, que urge por um profissional flexível, com competências e habilidades técnológicas e socioemocionais capazes de contribuir para o alcance dos objetivos organizacionais.

Diante do exposto, o estudo teve como objetivo, analisar a concepção de conhecimento defendida pela Gestão do Conhecimento presente no currículo do Ensino Médio. Conhecimento esse também defendido pela Gestão do Conhecimento nas organizações, para a manutenção da vantagem competitiva sustentável.

Para o alcance do objetivo proposto, foi realizada pesquisa bibliográfica, analítica e exploratória com abordagem qualitativa, que segundo Gil (2008) é desenvolvida com base em material já elaborado, constituído principalmente de livros e artigos científicos. Pesquisa Exploratória busca proporcionar maior familiaridade com o problema, no sentido de explicitá-lo, envolvendo o levantamento bibliográfico. A Lei no 13.415/2017, materializou o fazer escolar ao aprovar mudanças na Lei de Diretrizes e Bases da Educação Nacional, Lei no. 9.394/1996 (LDB 9.394/1996) e 
ratificar a Base Nacional Comum Curricular para o Ensino Médio (BNCC-EM), que prevê uma formação flexível mediada pelos itinerários formativos, um conhecimento de deva ser útil para resolver problemas da vida e preparação para o mundo do trabalho.

Logo, o estudo se justifica por abordar questões correlatas ao conhecimento tecnicista presente no currículo para a etapa do Ensino Médio, após a Lei no. 13.415/2017 em âmbito nacional. Currículo esse que deverá se efetivar até 2022 em todos os sistemas escolares, o que torna o estudo relevante.

\section{Gestão do conhecimento e educação: perspectivas tecnicista e utilitarista para a formação do sujeito do ensino médio}

$\mathrm{Na}$ atual fase do desenvolvimento do modo de produção - capital financeiro mundializado - são requisitados do sujeito conhecimentos para atender demandas sociais complexas do cotidiano considerado incerto, fluído e globalizado. Domínio de competências em inovações tecnológicas e habilidades socioemocionais são requisitados para contribuir favoravelmente para a captura e compartilhamento da informação, para a criação do conhecimento organizacional, próprias da Gestão do Conhecimento. Nesse sentido, objetiva-se apresentar a concepção de conhecimento que fundamenta o currículo escolar tecnicista e utilitarista ordenado pela Lei $\mathrm{n}^{\circ}$. 13.415/2017 que alterou a LDB n. 9.394/1996 e ratificou a BNCC-EM (Resolução no. 4 de 17 de dezembro de 2018), na formação do sujeito.

Ao analisar a fundamentação teórica e metodológica do currículo presente na BNCC-EM e na LDB no. 9.394/1996, faz-se necessário compreender quais são seus interlocutores, a considerar que deve ter clareza da função social precípua da escola, bem como, qual o cidadão que se deseja formar, para qual sociedade. Assim, tornase mister analisar o conteúdo da Lei e compreender quais são seus interlocutores contemporâneos e, então, compreender a estruturação do currículo necessário para a efetividade do proposto, compreendendo, ainda, a necessidade de gerir o conhecimento que assumiu centralidade dos debates entre gestores organizacionais, demandando investimentos em Gestão do Conhecimento e suas ferramentas de aprendizagens.

A Lei no. 13.415/2017, oriunda da Medida Provisória (MP) no. 746/2016, que trouxe mudanças para o currículo do Ensino Médio ao alterar a LDB no. 9.394, de 20 de dezembro de 1996, e ratificar a BNCC-EM, surgiu da necessidade em atender ao discurso hegemônico do fracasso do Ensino Médio, demarcado pelo baixo desempenho apresentado pelas avaliações internas e externas, bem como, pela alta taxa de evasão e abandono, distorção idade-série e ainda o acentuado número de jovens que nem estudam e nem trabalham, conforme expressa o documento do Ministério da Educação EM no 00084/2016/MEC (BRASIL, 2016).

Todo currículo escolar está ancorado em uma concepção teórico-metodológica que o fundamenta e o define. A partir deste são estabelecidas as metodologias didático-pedagógicas que são implementadas no processo de ensino e de aprendizagem, com vistas à formação integral do educando. As Diretrizes Curriculares para o Ensino Médio atualizadas pela Resolução CNE/CEB 3/2018, orientam que as opções metodológicas devam corresponder imediatamente a uma habilidade e/ou competência, como mostra: 
III - adotar metodologias de ensino e de avaliação de aprendizagem que potencializem o desenvolvimento das competências e habilidades expressas na BNCC e estimulem o protagonismo dos estudantes;

IV - organizar os conteúdos, as metodologias e as formas de avaliação, por meio de atividades teóricas e práticas, provas orais e escritas, seminários, projetos e atividades online, autoria, resolução de problemas, diagnósticos em sala de aula, projetos de aprendizagem inovadores e atividades orientadas, de tal forma que ao final do ensino médio o estudante demonstre: a) competências e habilidades na aplicação dos conhecimentos desenvolvidos; b) domínio dos princípios científicos e tecnológicos que estão presentes na produção moderna; c) práticas sociais e produtivas determinando novas reflexões para a aprendizagem; d) domínio das formas contemporâneas de linguagem (BRASIL, 2018b, p. 5, grifo nosso).

Cabe ressaltar que considerando a amplitude da Lei, pode-se supor que esta, em sua essência, não tem como preocupação principal, a formação integral dos alunos do Ensino Médio, mas uma amplitude de medidas as quais buscam adequar a oferta do Ensino Médio, aos ajustes econômicos do Estado neoliberal, com a adoção de parcerias, terceirizações e incentivo à privatização da educação pública. Estabelece redução de carga horária (de 2.400 para 1.800 horas) para integralização dos conteúdos da BNCC-EM, flexibiliza e orienta a metodologia didático-pedagógica e o currículo, ratificando a diversificação de componentes curriculares e instrumentos integradores do ensino, conforme o Art. 30, parágrafo $5^{\circ}$ da Lei no. 13.415/2017:

Art. 30 A Lei no 9.394, de 20 de dezembro de 1996, passa a vigorar acrescida do seguinte Art. 35-A § 5 A carga horária destinada ao cumprimento da Base Nacional Comum Curricular não poderá ser superior a mil e oitocentas horas do total da carga horária do ensino médio, de acordo com a definição dos sistemas de ensino. (BRASIL, 2017a, p. 1).

Na BNCC-EM as metodologias e as formas de avaliação processual serão exploradas com utilização de atividades diversificadas e conforme segue

[...] $\S 8^{\circ}$ Os conteúdos, as metodologias e as formas de avaliação processual e formativa serão organizados nas redes de ensino por meio de atividades teóricas e práticas, provas orais e escritas, seminários, projetos e atividades on-line, de tal forma que ao final do ensino médio o educando demonstre:

I - Domínio dos princípios científicos e tecnológicos que presidem a produção moderna;

II - Conhecimento das formas contemporâneas de linguagem. (Lei No 13.415/2017) (BRASIL, 2017a, p. 1).

Conforme mencionaram Pereira e Evangelista (2019, p. 78), a tecnologia da informação e comunicação, bem como às competências socioemocionais assumiram centralidade, "posição medular" na BNCC, compondo suas dez competências gerais. As competências socioemocionais, tais como o, exercício da empatia, resolução de 
conflitos e a cooperação, o agir pessoal e coletivamente, como resiliência determinação e autonomia, entre outros aspectos, aliadas às ferramentas tecnológicas concretizariam a educação para o século XXI ou sociedade do conhecimento.

Fato que encontra ressonância nos processos da Gestão do Conhecimento organizacional quando aplicada e sistematizada, no contexto organizacional, com vista aos ativos intangíveis e tangíveis, envolvendo Ciência e Tecnologia, para a promoção da comunidade escolar quanto a aquisição, elaboração e o compartilhamento do conhecimento (SANTOS; HOFFMANN, 2018). A escola busca, por meio da Gestão do Conhecimento, aprimorar os processos de aprendizagem escolar, uma vez que o conhecimento está na mente daquele aprende, estreitamente relacionado ao processo de aquisição da aprendizagem (CHENG, 2019). A inserção das tecnologias da informação e comunicação, a exemplo do uso de redes sociais digitais constituem-se em ambientes facilitadores para o compartilhamento do conhecimento e promoção a aprendizagem (URPIA et al., 2019).

Para a reprodução ideológica e produtiva do capital, é solicitado uma educação que forme os trabalhadores segundo os novos padrões de exploração do trabalho. Ao mesmo tempo, no nível ideológico, limitar as expectativas dos sujeitos em termos de socialização do conhecimento via escola, difundido a ideia de que o mais importante a ser adquirido por meio da educação não é o conhecimento, mas sim, a capacidade de constante adaptação às mudanças no sistema produtivo. Uma escola com ideário afinado à lógica do capitalismo contemporâneo (DUARTE, 2001, p. 72).

A concepção teórico-metodológica de conhecimento presente na Reforma da Educação se fundamenta na concepção da Sociedade do Conhecimento, que segundo Duarte (2001), sustenta princípios fundamentais, como o de que, o conhecimento já estaria totalmente democratizado para o conjunto da sociedade contemporânea, o que não corresponde com a veracidade, pois informação não corresponde ao conhecimento científico, ensinado na escola, desconsiderando a especificidade do conhecimento escolar.

Outro elemento aponta que, a capacidade de mobilizar conhecimentos para resolver problemas práticos da vida, é mais importante, que o acesso ao conhecimento científico, enfatizando o empreendedorismo e o esvaziamento da memória coletiva. Ainda, a negação do conhecimento como apropriação da realidade sistematizada teoricamente, mas uma criação de significados intersubjetivos, e que todos os tipos de conhecimento podem ajudar a explicar a realidade natural e social.

Nesse sentido, Ramos e Heinsfeld (2017) procuraram explicitar essa peculiaridade posta nessa atual Reforma da Educação, a qual não requer que o trabalhador desenvolva tão somente a capacidade de produzir mecanicamente uma atividade laboral, mas necessita ter consigo e em si, habilidades, tais como: sociabilidade, espírito de equipe e colaboração, tomada de decisões, conhecimento dos diferentes códigos e linguagens, entre tantas outras, que o capacite para contribuir nas organizações e fora delas também. Com competências e habilidades tecnológicas e socioemocionais de modo a fazer valer um currículo onde se reduz a carga horária em conteúdos básicos e privilegie articulações em áreas diversas com suas tecnologias, pois somente de posse desse conhecimento tecnológico, utilitário, embasado no saber fazer complementado com as habilidades socioemocionais esse trabalhador contribuirá com o desenvolvimento do país, leia-se, do capital. 
Uma escola que privilegia a articulação entre conteúdo - competência habilidade, promove o alinhamento e a prescrição da ação educativa a ser desenvolvida para o alcance da formação desejada, qual seja: munir o educando de um instrumental técnico, exigido para atuar no contexto social complexo e dinâmico.

A considerar a dinâmica no mundo do trabalho, as inovações tecnológicas e ênfase dada à informação na sociedade do conhecimento, fez-se necessário ressignificar o fazer pedagógico da e na escola norteado pelo acirrado desenvolvimento tecnológico determinado pelos condicionantes socioeconômicos.

A intensa e acelerada inovação tecnológica, a primazia do conhecimento na contemporaneidade e a fluidez nas relações de produção e consumo são necessidades imediatistas, que ditam os parâmetros para a formação dos sujeitos, capaz de tornálos aptos a realizar ações que respondam às necessidades produtivas. Conforme expõe Sampaio (2017, p. 347) o que se realiza de fato é uma "adaptação na funcionalização da escola e do ensino" em função das demandas do mercado.

Nesse sentido, o ato de ensinar e aprender requer novos contextos, novos instrumentos, novos arranjos dos saberes, novos ambientes de efetivação da aprendizagem, que possibilitem aos alunos experienciar, internalizar, inovar, socializar, continuar aprendendo e colaborar para a construção de uma sociedade harmônica e sustentável. Para tanto, a BNCCEM orienta procedimentos de ensino e de aprendizagem que favoreçam a experiência e a participação colaborativa, observa-se assim que as ferramentas de Gestão do Conhecimento, também são utilizadas na e pela escola para a criação do conhecimento técnico, em um movimento contínuo de aprendizagem no âmbito dos sistemas escolares.

Para tanto, o currículo escolar deve se constituir de um manual prescritivo (onde cada competência corresponda diametralmente a uma habilidade) com os conteúdos básicos definidores dessa preparação para o mundo do trabalho, o qual corresponde com as necessidades das organizações no contexto incerto da economia globalizada que urge por inovações, tornando sine qua non gestar adequadamente o conhecimento para a vantagem competitiva sustentável. Subtítulo: referencial teórico

\section{Metodologia}

Pesquisa bibliográfica, analítica e exploratória com abordagem qualitativa, que segundo Gil (2008) a pesquisa é desenvolvida com base em material já elaborado, constituído principalmente de livros e artigos científicos. A pesquisa qualitativa se ocupa nas ciências sociais, com o nível de realidade que não pode ser quantificado, envolve o universo de significados, motivações, valores e atitudes o que corresponde com o espaço mais profundo das relações e dos fenômenos sociais (MINAYO, 2001). A pesquisa exploratória busca proporcionar maior familiaridade com o problema, no sentido de explicitá-lo, envolvendo o levantamento bibliográfico e estudo de caso. Para a consecução da pesquisa e do seu caráter de cientificidade, foi desenvolvida segundo uma metodologia e respectivos procedimentos necessários à efetivação. Todos os temas foram analisados por meio de uma revisão analítica de bibliografias correlatas aos assuntos, em especial o texto da Lei no. 13.415 de 16 de fevereiro de 2017, a Base Nacional Curricular para o Ensino Médio, a Lei de Diretrizes e Base da Educação Nacional (LDBEN/9394/1996). Sobre a Gestão do Conhecimento as referências centrais foram as obras de Ikujiro Nonaka e Hirotaka Takeuchi (1997) 
"Criação de conhecimento na empresa" e, a obra de Chun Wei Choo (2003) "A Organização do Conhecimento: Como as organizações usam a informação para criar significado, construir conhecimento e tomar decisões". Buscou-se a Gestão do Conhecimento, no sentido de defini-la, e identificar qual tipo de conhecimento é por ela defendido, discutir sobre as práticas de Gestão do Conhecimento organizacional. E analisar a relação dessas práticas com a educação, após a Lei no. 13.415/2017, que pressupõe a preparação do indivíduo para o mundo do trabalho na contemporaneidade.

\section{Resultados e discussões}

O conhecimento na perspectiva da Gestão do Conhecimento organizacional pode ser considerado ferramenta para o mapeamento de conhecimento, sobretudo, aqueles que são úteis para as organizações. Peter Drucker (1990) define Gestão do Conhecimento como capacidade de gerenciar, descobrir, mapear, classificar, captar, distribuir, multiplicar e reter conhecimento, com eficiência, eficácia e efetividade para garantir a vantagem competitiva sustentável e sobrevivência do negócio.

Para tanto, os teóricos da Gestão do Conhecimento elaboraram modelos de gestão, dentre eles, destacam-se os modelos defendidos por Nonaka e Takeuchi (1997), e o modelo de Choo (1998). O modelo denominado por Espiral do Conhecimento foi desenvolvido por Nonaka e Takeuchi (1997), para esses autores a dimensão tácita e explícita do conhecimento se complementam, é dessa interação que se origina o conhecimento organizacional. A natureza subjetiva da ação humana está ancorada nos sistemas de compromissos, crenças e valores dos indivíduos, elementos indispensáveis à formação da teoria do conhecimento organizacional, fortalecendo a premissa básica de que o capital intelectual no fator capital humano constitui o maior ativo das organizações do conhecimento. Tanto a informação quanto - conhecimento pressupõem a interação social entre os colaboradores, uns influenciando a maneira de pensar, conjecturar, experienciar, motivar para insights e inovar.

No contexto da sociedade do conhecimento, o capital humano vincula-se ao conhecimento das pessoas e dos resultados advindos desse conhecimento, "a inteligência humana e os recursos intelectuais constituem permanentemente os ativos mais valiosos de qualquer empresa" (EDVINSSON; MALONE, 1998, p. 2). Disso decorre a necessidade de formação dos sujeitos que irão compor o ativo intangível das organizações.

\section{Considerações finais}

A concepção de educação concernente ao modo de produção na sociedade do conhecimento se materializa nas políticas educacionais e no fazer escolar, ditando uma forma de Gestão do Conhecimento também no âmbito das escolas. Um conhecimento que seja útil para o enfrentamento dos condicionantes socioeconômicos e que contribua com o alcance da vantagem competitiva nas organizações.

A análise da Lei no. 13.415/2017 emanada da necessidade de reformar o Ensino Médio que ordenou alterações na LDB n. 9.394/1996 e ratificou a BNCC-EM prima por uma educação flexível e utilitária, pragmatista e tecnológica que corresponda às 
demandas necessárias ao protagonismo juvenil, na construção de seu projeto de vida e preparação para o mundo do trabalho.

Considerando que o currículo do Ensino Médio deverá atender ao contido na LDB no. 9.394/1996 e pela BNCC-EM com seus itinerários formativos, esse modelo de currículo confere relevância para o contexto local e as possibilidades dos sistemas de ensino, traz como desafio a construção de currículo e elaboração de proposta pedagógica compostos, tendo como obrigatoriedade a perspectiva flexível para a formação de competências e habilidades, ordenando a substituição do modelo de currículo único, por um modelo diversificado e flexível, composto pela BNCC-EM e Itinerários formativos, com diferentes arranjos curriculares.

A análise do documento apontou que a formação por competências definida como mobilização de conhecimentos (conceitos e procedimentos) e habilidades (práticas, cognitivas e socioemocionais), atitudes e valores, objetiva a formação de sujeitos aptos a corresponder às exigências do processo produtivo.

Assim, percebe-se que é possível identificar aspectos da Gestão do Conhecimento presentes na BNCC-EM quando o documento destaca a ênfase do protagonismo do aluno, respeito às subjetividades, flexibilização da oferta do ensino, no desenvolvimento de habilidades cognitivas e socioemocionais, compreensão dos fundamentos científico-tecnológicos dos processos produtivos, para os sujeitos que aprendem. Além disso, a cooperação e compartilhamento de conhecimentos com ênfase em empreendedorismo, que possam contribuir eficazmente para a maximização do capital intelectual e consequentemente, do capital financeiro das organizações que aprendem, da sociedade do conhecimento.

Dessa forma, sujeitos flexíveis, protagonistas, criativos são indispensáveis, pois compõem o capital intelectual das organizações. Dada a ênfase ao conhecimento tácito (ativo intangível) e sua conversão em conhecimento explícito, socialização e compartilhamento, também a Gestão do Conhecimento se constitui em ferramentas prescritivas que direcionam o percurso da criação do conhecimento no contexto das organizações.

\section{REFERÊNCIAS}

BRASIL. Base Nacional Comum Curricular (BNCC). Brasília (DF): Ministério da Educação, $2018 a$. Disponível em:

http://basenacionalcomum.mec.gov.br/images/BNCC_EI_EF_110518_versaofinal_site.pdf. Acesso em: 13 jul. 2019.

BRASIL. Conselho Nacional de Educação. Câmara de Educação Básica. Resolução No 3, de 21 de novembro de 2018. Atualiza as Diretrizes Curriculares Nacionais para o Ensino Médio, observadas as alterações introduzidas na LDB pela Lei no 13.415/2017. Diário Oficial da União, Brasília, 21 nov. 2018b, Seção 1, p. 49. Disponível em: http://portal

.mec.gov.br/index.php?option=com_docman\&view=download\&alias=102311-pceb003-

18\&category_slug=novembro-2018-pdf\&Itemid=30192. Acesso em: 10 abr. 2020.

BRASIL. Lei no 13.415, de 16 de fevereiro de 2017a. Altera as Leis nos 9.394, de 20 de dezembro de 1996, que estabelece as diretrizes e bases da educação nacional, e 11.494, de 20 de junho 2007, que regulamenta o Fundo de Manutenção e Desenvolvimento da Educação Básica e de Valorização dos Profissionais da Educação, a Consolidação das Leis do Trabalho - CLT, aprovada pelo Decreto-Lei $\mathrm{n}^{\circ}$ 5.452, de $1^{\circ}$ de maio de 1943, e o Decreto-Lei no 236, de 28 de fevereiro de 1967; revoga a Lei n० 11.161, de 5 de agosto de 2005; e institui a Política de Fomento à Implementação de Escolas de Ensino Médio em Tempo Integral. Diário Oficial da União, Brasília, 17 fev 2017a. Disponível em: 
http://www.planalto.gov.br/ccivil_03/_Ato2015-2018/2017/Lei/L13415.htm. Acesso em: 09 mar. 2020.

BRASIL. Lei No 9.394, de 20 de dezembro de 1996. Estabelece as diretrizes e bases da educação nacional. Diário Oficial da União, de 23 de dezembro de 1996. Disponível em: http://www.planalto.gov.br/ccivil_03/leis/19394.htm. Acesso em: 10 abr. 2020.

BRASIL. Lei no. 12.796, de 4 de abril de 2013. Altera a Lei no 9.394, de 20 de dezembro de 1996, que estabelece as diretrizes e bases da educação nacional, para dispor sobre a formação dos profissionais da educação e dar outras providências. Diário Oficial da União, 5 abr. 2013. Disponível em: http://www.planalto.gov.br/ccivil_03/_Ato2011-2014/2013/Lei/L12796.htm. Acesso em: 20 abr. 2020.

BRASIL. Ministério da Educação. Conselho Nacional de Educação Conselho Pleno. Resolução No 4 de 17 de dezembro de 2018. Institui a Base Nacional Comum Curricular na Etapa do Ensino Médio (BNCC-EM), como etapa final da Educação Básica, nos termos do artigo 35 da LDB, completando o conjunto constituído pela BNCC da Educação Infantil e do Ensino Fundamental, com base na Resolução CNE/CP no 2/2017, fundamentada no Parecer CNE/CP n० 15/2017. Diário Oficial da União, Brasília, 18 de dezembro de 2018c, Seção 1, p. 120 a 122. Disponível em: http://www.in.gov.br/materia/-/asset_publisher/Kujrw0TZC2Mb/content/id/55640296. Acesso em: 10 abr. 2020.

BRASIL, Ministério da Educação - MEC. EM no. 00084/2016/MEC. Brasília, 15 de setembro de 2016. Disponível em: http://www.planalto.gov.br/ccivil_03/_Ato2015-2018/2016/Exm/Exm-MP746-16.pdf. Acesso em: 10 abr. 2020.

CHENG, Eric C. K. Successful Transposition of Lesson Study: A Knowledge Management Perspective. New York: Springer, 2019. Disponível em:

https://books.google.com.br/books/about/Successful_Transposition_of_Lesson_Study.html?id=hQRr DwAAQBAJ\&source=kp_cover\&redir_esc=y Acesso em: 10 abr. 2020.

CHOO, Chun Wei. A Organização do Conhecimento: como as organizações usam a informação para criar significado, construir conhecimento e tomar decisões. Tradução Eliana Rocha. São Paulo: Senac, São Paulo, 2003.

$\mathrm{CHOO}$, Chun Wei. The Knowing Organization: how organizations use information for construct meaning, create knowledge and make decisions. Nova Iorque: Oxford Press, 1998. 354p.

DALKIR, Kimiz. Knowledge management in theory and practice. Massachusetts: Elsevier, 2005. $372 p$.

DAVENPORT, Thomas H.; PRUSAK, Laurence. Conhecimento empresarial: como as organizações gerenciam seu capital intelectual. 7. ed. São Paulo: Campus, 1998.

DRUCKER, Peter F. Inovação e espírito empreendedor (entrepreneurship): prática e princípios. Tradução de Carlos Malferrari. São Paulo: Pioneira Thomson, 2003. 400p.

DUARTE, Newton. Vigotski e o "aprender a aprender": crítica às apropriações neoliberais e pósmodernas da teoria vigotskiana. 2. ed. Campinas, SP: Autores Associados, 2001. 353p. Disponível em:

http://www.afoiceeomartelo.com.br/posfsa/Autores/Duarte,\%20Newton/Vigotski\%20e\%20o\%20Apr ender\%20a\%20Aprender.pdf. Acesso em: 10 mai. 2020.

MINAYO, Maria Cecília de Souza (Org). Pesquisa Social. Teoria, método e criatividade. 18 Ed. Petrópolis: Vozes, 2001.

NONAKA, Ikujiro, TAKEUCHI, Hirotaka. Criação do Conhecimento na empresa: como as empresas japonesas geram dinâmica da inovação. Rio de Janeiro: Campus. 1997. 
NONAKA, Ikujiro. A empresa criadora de conhecimento. In: TAKEUCHI, Hirotaka. NONAKA, Ikujiro. Gestão do conhecimento. Porto Alegre: Bookman, 2008. p. 39-53.

PEREIRA, Jennifer Nascimento; EVANGELISTA, Olinda. Quando o Capital educa o educador: BNCC, Nova Escola e Lemann. Movimento-Revista de Educação, Niterói, v. 6, n.10, p. 65-90, jan./jun. 2019.

RAMOS, Flávia Regina Oliveira; HEINSFELD, Bruna Damiana de Sá Sólon. Reforma do Ensino Médio de 2017 (Lei No 13.415/2017): um estímulo à visão utilitarista do conhecimento. In: CONGRESSO NACIONAL DE EDUCAÇÃO - EDUCERE, 13. 2017. Anais... Curitiba, PR: Educere, 2017. Disponível em: https://educere.bruc.com.br/arquivo/pdf2017/24107_11975.pdf. Acesso em: 14 maio 2020.

SAMPAIO, Carlos Thiago Gomes. A Pedagogia das Competências e o Ensino de Geografia. Revista Brasileira de Educação em Geografia, Campinas, v. 7, n. 13, p. 343-358, jan./jun., 2017. Disponível em: http://www.revistaedugeo.com.br/ojs/index.php/revistaedugeo/article/view/365. Acesso em: 20 abr. 2020.

SANTOS, Cintia Almeida da Silva. HOFFMANN, Wanda Aparecida Machado. Modelo de Gestão do Conhecimento para Organizações de Educação Profissional e Tecnológica: versão conceitual. Revista CEREUS, v.10, n. 4, 2018. Disponível em: http://ojs.unirg.edu.br/index.php/1/article/view/1920. Acesso em: 26 maio. 2020.

URPIA, Arthur Gualberto Bacellar da Cruz; FORNO, Letícia Fleig Dal, BORTOLOZZI, Flávio, MASSUDA, Ely Mitie, FACCIN, Tatiana Carla. As Redes Sociais e sua Utilização como

Ferramentas para as práticas de Gestão do Conhecimento: uma análise em escolas públicas do Paraná. Perspectivas em Diálogo: Revista de Educação e Sociedade, v. 6 n. 13,2019. Disponível em: https://periodicos.ufms.br/index.php/persdia/article/view/8070 Acesso em: 26 maio. 2020.

Recebido em: 28 de maio de 2020.

Aceito em: 06 de agosto de 2020. Publicado em: 05 de janeiro de 2021. 